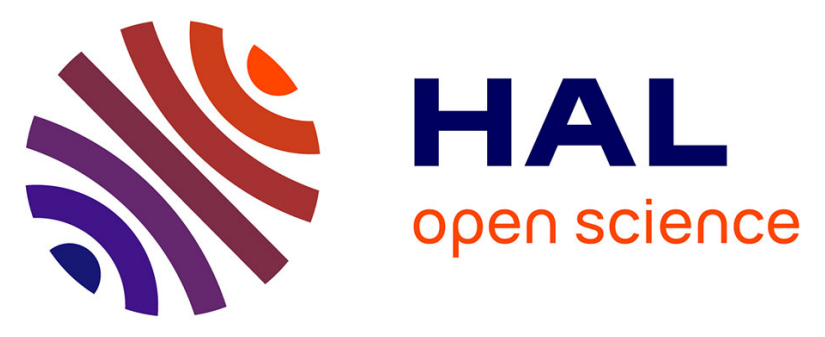

\title{
Feasibility of the Current-Duration Approach to Studying Human Fecundity.
}

Rémy Slama, Béatrice Ducot, Lisbeth Carstensen, Christine Lorente, Elise de La Rochebrochard, Henri Leridon, Niels Keiding, Jean Bouyer

\section{- To cite this version:}

Rémy Slama, Béatrice Ducot, Lisbeth Carstensen, Christine Lorente, Elise de La Rochebrochard, et al.. Feasibility of the Current-Duration Approach to Studying Human Fecundity.: Feasibility of the Current-Duration Approach. Epidemiology, 2006, 17 (4), pp.440-449. 10.1097/01.ede.0000221781.15114.88 . inserm-00000056

\section{HAL Id: inserm-00000056 https://www.hal.inserm.fr/inserm-00000056}

Submitted on 31 Aug 2006

HAL is a multi-disciplinary open access archive for the deposit and dissemination of scientific research documents, whether they are published or not. The documents may come from teaching and research institutions in France or abroad, or from public or private research centers.
L'archive ouverte pluridisciplinaire $\mathbf{H A L}$, est destinée au dépôt et à la diffusion de documents scientifiques de niveau recherche, publiés ou non, émanant des établissements d'enseignement et de recherche français ou étrangers, des laboratoires publics ou privés. 


\section{Feasibility of the Current-Duration Approach to Studying Human Fecundity}

Abbreviated running title: Feasibility of the Current-Duration Approach

Abstract: 247 words

Main text: 4499 words

\section{Authors:}

Rémy Slama ${ }^{1}$, Béatrice Ducot ${ }^{1}$, Lisbeth Carstensen ${ }^{2}$, Christine Lorente ${ }^{3}$, Elise de La Rochebrochard ${ }^{1}$, Henri Leridon ${ }^{1}$, Niels Keiding ${ }^{2}$, Jean Bouyer ${ }^{1}$

\section{Affiliations:}

1: Inserm, National Institute of Health and Medical Research, U569, IFR 69, Le KremlinBicêtre, France; Ined, National Institute for Demographic Studies; University Paris 11, Faculté de Médecine, Le Kremlin-Bicêtre, France.

2: Department of Biostatistics, University of Copenhagen, Copenhagen, Denmark.

3: InVS, Institut de Veille Sanitaire, Département Santé-Environnement, Saint-Maurice, France.

Address correspondence to Rémy Slama, Inserm U569, 82 rue du Général Leclerc, F-94276

Le Kremlin-Bicêtre CEDEX, France. E-mail: slama@vjf.inserm.fr, Phone: +33-145-21-2343, Fax: +33-145-21-20-73.

Financial support:

The study was funded by grants from Institut de Veille Sanitaire (InVS) and from the French Agency for Environmental and Occupational Health Safety (AFSSET). 


\section{ABSTRACT}

Approaches for monitoring time trends in couples' fecundity and for studying its sensitivity to environmental factors are needed. Two approaches rely on the inclusion of a cross-sectional sample of couples currently "at risk" of pregnancy, either with follow-up (prevalent cohort) or without follow-up (current-duration design). To illustrate the feasibility of the current-duration design, we contacted a random sample of 1,204 French women age 18-44 years in 2004, and recruited those who currently had unprotected sexual intercourse. The current duration since the beginning of unprotected intercourse (CDUI) was defined for 69 women (5.7\%). An additional 15 women (1.2\%) were planning to start trying to become pregnant within the next six months. A parametric approach allowed, from CDUI, to estimate fecundity as if the couples had been followed prospectively. The estimated proportion of couples not pregnant after 12 months of unprotected intercourse was 34\% (95\% confidence interval [Cl], 15-54\%). The accelerated-failure time model allows study of the influence of environmental factors on fecundity. As an illustration, tobacco smoking by the woman was associated with a doubling in the median duration of unprotected intercourse before pregnancy (adjusted time ratio $=2.4$, $95 \% \mathrm{Cl}=1.1-5.2)$. We quantified the influence of time trends in the prevalence of smoking. We suggest ways to quantify or avoid other potential bias. In conclusion, it is possible to recruit a sample of couples currently having unprotected intercourse. The current-duration design appears feasible, with about 5 times as many women eligible for study as for an incident cohort design. 


\section{INTRODUCTION}

Fecundity, the biological ability to conceive a live birth, is an important notion in reproductive health. Biologically, fecundity depends on several factors: the quality of gametogenesis, the migration of the spermatozoa to the ovocyte, fertilization, implantation, and survival of the conceptus. ${ }^{1,2}$ From the point of view of public health, fecundity conditions the couples' decision to seek medical help for infertility, leading to possible painful and expensive treatments. Male reproductive health is likely to worsen, ${ }^{3}$ which may have consequences on the couples' fecundity ${ }^{4}$ concerns about the influence of environmental pollutants on human reproduction also exist. ${ }^{3}$ Thus, there is a need for efficient approaches for monitoring time trends in fecundity ${ }^{5,6}$ and for studying its susceptibility to environmental pollutants.

Couples' fecundity has been most often estimated using the pregnancy-based approach, in which time to pregnancy (TTP), the number of months of unprotected intercourse before conception, is retrospectively assessed among couples who eventually have a detected pregnancy. ${ }^{1,7}$ In this approach, couples remaining childless are excluded. This exclusion induces an over-estimation in the fecundity level, and may bias the estimated influence on fecundity of environmental ${ }^{8}$ and biological factors (such as semen parameters ${ }^{4}$ or $_{\text {age }}{ }^{9,10}$ ). The "classical" (incident) cohort approach ${ }^{2,11-13}$ does not have this limitation. It consists in recruiting couples before they start unprotected intercourse and following them to monitor the occurrence of a pregnancy. However, this approach lacks a well-defined sampling-frame, making it difficult to quantify participation rates and to study possible selection bias. ${ }^{13-15}$ Moreover, the proportion of eligible women (those planning to start a pregnancy attempt within, say six months) may be quite low. This is typically around $1 \%$ of women of reproductive age in Western countries. ${ }^{13}$

Another possibility is to include unsuccessful attempts at pregnancy in a retrospective study (historically prospective design, Figure 1). ${ }^{7,16}$ However, the quality of recall of the occurrence and duration of such unsuccessful attempts at pregnancy has not been assessed and may be poor. Alternative designs are therefore worth being considered. 
Several designs already proposed but apparently never explicitly applied rely on the inclusion of couples during the period of unprotected intercourse. ${ }^{17-20}$ They can either be followed-up to monitor the occurrence of a pregnancy, which corresponds to a prevalent cohort design, ${ }^{18,21}$ or not followed up, which corresponds to the current-duration design. ${ }^{17,20}$ Here, we will focus on the current-duration design. In this design, since women are included before the detection of a pregnancy and not followed-up, TTP is right-censored for all observations. This censored duration, which we will call "current duration of unprotected intercourse" (or current duration), corresponds to the time elapsed between the beginning of unprotected intercourse and inclusion in the study. The design also implies truncation and length-biased sampling. Specific statistical approaches allow to deal with these features; they rely on the theory of backward recurrence times, either in a discrete ${ }^{20}$ or continuous time setting. ${ }^{17}$ They allow the survival function corresponding to the total duration of unprotected intercourse to be estimated from the observed distribution of current duration, as if the couple had been followed-up until the end of the period of unprotected intercourse. The idea is analogous to the well-known demographic result that in a stationary population the crosssectional age distribution at any fixed time is proportional to the life-table or survival function that would be obtained by following up a birth cohort. A class of survival regression models can be used to estimate the influence of environmental factors on fecundity in this setting. ${ }^{22,23}$ A major advantage of this approach is that couples eventually infertile (i.e. childless) are included. Possible advantages over the prospective approach are a possibly higher eligibility rate and a clearly defined sampling frame that does not require the couples to know in advance when they will start an attempt at pregnancy.

The Observatory of Fecundity in France was set up to describe the fecundity of couples living in France, and to study the influence of environmental factors on human fecundity. The present paper presents results from a preliminary study and aims to evaluate the feasibility of including a cross-sectional sample of couples with unprotected intercourse. We also discuss the possible uses, interest, limitations and bias of the current-duration approach. 


\section{RECRUITMENT OF A CROSS-SECTIONAL SAMPLE OF SEXUALLY ACTIVE NON- CONTRACEPTING COUPLES}

\section{Eligibility criteria}

The novel aspect of the sampling frame of the current-duration approach is that couples are recruited during the period they are "at risk" of pregnancy -the period of unprotected intercourse- and not before (classical prospective studies) or afterwards (retrospective approaches).

We recruited couples during a phone survey in March and April 2004. We drew a random sample of listed and unlisted land-line phone numbers covering the entire country of France, and then we sent an information letter to the addresses corresponding to the listed numbers. Computer-assisted telephone interviews were conducted by 15 trained interviewers. Each phone number was dialed up to 15 times at different times and on different days. An address was considered eligible if it was the principal residence of a French-speaking woman age 18-50 years. In homes with more than one woman age 18-50 years, we selected the one whose birthday was the soonest. This woman then answered an eligibility questionnaire of less than 15 questions. ${ }^{24}$ For the current-duration approach, women were eligible if they were age 18-44 years at interview, declared not to be pregnant, currently had a male partner, had had sexual intercourse within the last two months, did not use any birthcontrol method (including sterilization of either partner), and had not given birth to a live or still born baby in the 3 months before the interview. We included women who had unprotected intercourse and declared not to be trying to become pregnant, but in a secondary analysis we focused on couples who were trying to become pregnant at the beginning of the period of unprotected intercourse.

Among the 7,699 dialled phone numbers, 4,313 were principal residences, among which 136 subjects $(3.2 \%)$ immediately declined to participate (Table 1$)$. Among the remaining residences, $41 \%$ included a woman age $18-50$ years. Of these women, $88 \%$ answered the eligibility questionnaire, with 1,204 being women age 18-44 years (Table 1). 
Among these 1,204 women, 91 were eligible. Five women declined to answer our detailed questionnaire. We excluded 11 couples who had undergone a medical treatment for infertility at some time since the beginning of the period of unprotected intercourse. We excluded them because a medical treatment could modify the probability of pregnancy, which is similar to censoring in prospective TTP studies. This left 75 women for whom we could in principle define current duration.

\section{Current Duration of Unprotected Intercourse}

Current duration was defined as the time elapsed from the date of cessation of use of the last birth control method until the interview. This duration was converted into months without rounding. When the date of cessation was unknown, we used the duration elapsed since the last time the couple used birth control methods. When women stated that they had waited a certain time after ceasing contraceptive use before really trying to become pregnant (e.g. two months of periodic abstinence), we subtracted this time from current duration. If the woman had not used any birth control method since her last pregnancy, the current duration was defined as the duration from the end of the last pregnancy until interview, minus three months if the last pregnancy resulted in a live or still birth to account for post-partum infecundity. We made no distinction according to the duration of breast-feeding, but this could be done in future studies.

Among the 75 eligible women, we had to exclude two women with unknown current duration and four women who had never used contraception and had never been pregnant; we recommend that they be included in future studies by asking when they had first intercourse with their current partner. Thus, current duration was finally defined for 69 women $(5.7 \%$ of all women age $18-44$ years, $95 \%$ confidence interval $[\mathrm{Cl}]=4.4-7.0 \%)$. The eligibility rate may differ in countries with fertility rates or desired family size that are different from those in France.

In addition, out of the 1204 contacted women age $18-44$ years, $1.2 \%(95 \% \mathrm{Cl}=0.6-1.9 \%)$ stated that they planned to start a pregnancy attempt within 6 months (Table 2). Thus, had 
we conducted a "classical" (incident) prospective study, the eligible group would have been the subgroup of these $1.2 \%$ of couples who would eventually start the attempt at pregnancy and who would agree to be followed-up. This may correspond to about $1 \%$ of all women age 18-44 years. In a Danish study of first-pregnancy planners from whom biological samples were collected, there were 52,255 contacted women age 20-35 years who were cohabiting with a male partner and had no children. Of these, 851 women were planning to discontinue contraception to achieve a pregnancy (1.6\%). ${ }^{13,26}$ This rate is higher than our estimate of $1.2 \%$, but was computed among a population of young childless women with a male partner.

\section{CURRENT DURATION AND PROBABILITY OF PREGNANCY}

The median current duration was 11.3 months $\left(25^{\text {th }}\right.$ and $75^{\text {th }}$ percentiles $=4.0$ and 52.0 months; mean $=31.6$ months). Due to the sampling frame, this raw distribution cannot be compared with that of TTP collected in retrospective or prospective studies.

We estimated the survival function of the total duration of unprotected intercourse from current duration using a parametric approach relying on the Pareto distribution. ${ }^{17} \mathrm{We}$ constructed $95 \%$ confidence limits using the delta method. The estimated proportions of couples not pregnant after 12 and 24 months without using contraception were 34\% (95\% $\mathrm{Cl}=15-54 \%)$ and $16 \%(4-29 \%)$, respectively; the median survival was 7 months (Figure $2 \mathrm{~A}$ ). We repeated the analysis for the 53 couples (called "pregnancy planners") who had reported either that they were currently willing to become pregnant or that they had stopped contraception in order to become pregnant, even if they declared that they did not desire to become pregnant currently. Among these, $26 \%$ of the couples $(95 \% \mathrm{Cl}=10-42 \%)$ were not pregnant within 12 months of unprotected intercourse and 10\% (2-18\%) within 24 months (median survival= 5 months; Figure 2B).

Our fecundity estimates may appear low compared with other studies. However, caution is needed in comparisons because our inclusion criteria were based on the couples having unprotected intercourse rather than on couples being fertile or planning to become pregnant. 
Moreover, couples who had not been using any birth control method since their last pregnancy were included; these couples may overall have a lower fecundity than couples who previously used a birth control method. ${ }^{27}$ Among Danish first-pregnancy planners who were followed-up from the cessation of contraception, the proportion of couples not pregnant within six months of attempting was $38 \%,{ }^{2,4}$ compared with $47 \%(95 \% \mathrm{Cl}=28-66 \%)$ in our population restricted to the pregnancy planners.

\section{INFLUENCE OF ENVIRONMENTAL FACTORS ON FECUNDITY IN THE CURRENT- DURATION DESIGN}

If the underlying (unobserved) total durations of unprotected intercourse follow the structure of an accelerated-failure-time (AFT) model, then the observed current durations will follow the same structure. ${ }^{22,23}$ Consequently, the influence of covariates on current duration estimated by an AFT model is also an estimate of the influence of the covariates on the total duration of unprotected intercourse. Using this property, we illustrate the use of the currentduration approach to highlight the influence of environmental factors on fecundity, with women's smoking at the beginning of the period of unprotected intercourse as the exposure. The median current duration was nine months for non-smokers and 24 months for smokers. We fitted an AFT model (streg function, Stata 8.2, Stata Corp, College Station, TX):

$$
\log \left(C D U I_{i}\right)=\alpha+\beta X_{i}+\varepsilon_{i}
$$

The distribution of the survival function was chosen by comparing the confidence intervals estimated by the AFT model with bootstrap confidence intervals ( 8.2) for various distributions (not shown). ${ }^{28}$ The chosen distribution for current duration was the log-normal distribution. Consequently, this model was equivalent to linear regression on the log-transformed current durations. ${ }^{29}$ The time ratios corresponding to $\exp (\beta)$ and 
associated with the vector of covariates $\mathrm{X}$ can be interpreted as the ratios of the median values of the (unobserved) total durations of unprotected intercourse between the compared groups. For example, a time ratio of 2 corresponds to the median of the total duration of unprotected intercourse doubling for exposed compared to unexposed subjects. The adjusted effect of women's smoking corresponded to an increase in the median total duration of unprotected intercourse without pregnancy of $140 \%$, compared with non-smokers (time ratio $=2.4 ; 95 \% \mathrm{Cl}=1.1-5.2$ ). We also observed an unexpected possible trend towards a decreasing duration of unprotected intercourse with increasing maternal age (Table 3).

\section{SOURCES OF BIAS IN THE CURRENT-DURATION APPROACH}

Although our estimate of the effect of smoking on fecundity was coherent with other studies, ${ }^{30}$ it might well be biased. There are several types of bias inherent in fecundity studies, ${ }^{31-33}$ summarized in Table 4. We illustrate here how some of these biases can be handled with the current-duration approach.

\section{Time trends in initiation times}

The statistical analysis of the current duration assumes a uniformity over time for the initiation of periods of unprotected intercourse. ${ }^{17,20}$ In a pregnancy-based TTP study in five European countries, the distribution of starting dates for planned pregnancies varied with season; for most countries, more attempts at pregnancy started in summer and fewer attempts in the autumn. ${ }^{34}$ We propose weighting the population to estimate the amplitude of the bias due to seasonal variations in the number of initiations of pregnancy attempts. We assumed that initiations were unevenly distributed over the seasons and gave each subject a weight that was inversely proportional to the assumed distribution of initiation times for the whole population (24.5\% of periods of unprotected intercourse starting from January to March, $26.0 \%$ from April to June, $28.1 \%$ from July to September, and $21.4 \%$ from October to December $^{34}$ ). We re-estimated the AFT model using this weighted population. We found little 
variation from the unweighted results for the estimated effect of smoking (adjusted time ratio $=2.47,95 \% \mathrm{Cl}=1.20-5.08$; this is a change by $3 \%$ in time ratio). Seasonal variations in initiation times are thus unlikely to have biased the estimated effect of tobacco.

\section{Time trends in exposure}

Periods of unprotected intercourse that started a long time before the study have long current durations, whereas those that started recently have short current durations. Since exposure is assessed at the beginning of the period of unprotected intercourse, if there is a time trend in the prevalence of exposure, this pattern may bias the apparent association between exposure and fecundity, as for the retrospective designs. ${ }^{32}$ Weinberg and colleagues ${ }^{32}$ proposed a simulation approach using external data on time trends in the prevalence of the exposure to test whether the time trend can explain the association between fecundity and the exposure factor. We used this approach in the case of tobacco smoking. Using data on 26-to-34 year-old women from the general population, we assumed that the prevalence of smoking at the beginning of the period of unprotected intercourse was $43.2 \%$ in $1992,42.5 \%$ in $1999,{ }^{35}$ and $36.3 \%$ in 2004 (J.M. Wilquin, Inpes, Baromètre Santé, personal communication). We linearly interpolated or extrapolated the prevalence for the remainder of the 1990-2004 period.

Based on these time trends in the prevalence of smoking and assuming a lack of real effect of smoking on fecundity, the empirical distribution of the time ratio associated with smoking adjusted for the variables of Table 3 had a mean of 1.18 , and an empirical $95 \%$ confidence interval of 0.49 to 2.66 ( 1,000 replications). Our estimate of 2.40 from the model ignoring time trends corresponded to the $96^{\text {th }}$ percentile of this distribution. This gave a $p$-value corrected for time-trends in smoking of $8 \%$ (two-tailed test), compared with $3 \%$ before correction. Thus, time trends in the prevalence of women's smoking might explain a part of our observed association between smoking and fecundity.

As for pregnancy-based TTP studies, this approach assumes that the external data on the prevalence of exposure apply to couples starting a period of unprotected intercourse. This 
assumption may not hold for exposures for which couples think they may influence their fecundity.

\section{Differential persistence in trying and medical intervention bias}

The statistical analysis of current duration gives an estimate of the survival distribution of the (unobserved) total duration of unprotected intercourse, and of the influence of covariates on this duration. Strictly speaking, this duration is the minimum duration between the initiation of unprotected intercourse and either the detection of a pregnancy -not its conception- or the occurrence of a censoring event. This censoring event can be the start of a fecundity treatment, the separation of the couple, or the resumption of methods to avoid pregnancy. ${ }^{17}$ Thus, the current-duration approach cannot distinguish between attempts ending in a pregnancy and attempts ending for other reasons. In other words, the approach assumes that there is no difference between the compared groups in the persistence of trying to become pregnant and in the proportion of couples resorting to infertility treatments. This may not hold for all covariates; for example, women older than 40 years may give up attempting to become pregnant more quickly or start fertility treatment sooner than younger women. ${ }^{31}$ In our study, we observed a possible trend towards a shorter duration of unprotected intercourse with increasing female age (Table 3). If real, this unexpected association between fecundity and age, which is similar to that observed in some pregnancy-based TTP studies, ${ }^{9,10}$ may result from differences in the persistence in trying to become pregnant between couples of various ages.

Such a bias could be tested by re-contacting and questioning the included couples (e.g. 12 months after inclusion), and checking with survival models for differences across exposure levels in the probability of stopping having unprotected intercourse or of starting infertility treatments conditionally on the absence of pregnancy. ${ }^{31}$

\section{Pregnancy recognition bias}


Some women may be pregnant at the time of inclusion without knowing it. These women should be excluded (if the pregnancy lasts until detection), but they cannot be identified by questionnaire without follow-up. As a consequence, the survival function provided by our approach corresponds to time until pregnancy detection (or end of the period of unprotected intercourse for another reason), and not to time to pregnancy. For etiologic studies, this may create a bias if the delay in pregnancy recognition is not uniform across levels of exposure. Therefore, as for other types of TTP studies, differences between levels of exposure in how early couples detect pregnancies should be considered (by following up a sub-sample of the couples, for example).

\section{Pregnancy-wantedness bias}

The existence of unplanned and unwanted pregnancies constitutes a potential source of bias in all types of fecundity studies. Pregnancy planning and pregnancy wantedness biases correspond to several situations (Table 4): first, to the potential bias due to the exclusion of pregnancies occurring among couples using a contraceptive method (even sporadically), for which time to pregnancy -or current duration- cannot be defined; and second, to the bias stemming from the couples retrospectively describing as planned an unplanned pregnancy, a situation specific to retrospective designs. ${ }^{7,27}$ These terms can also be used to describe the bias potentially stemming from the exclusion of couples who have unprotected intercourse without declaring to be willing to be pregnant. These couples might be atypical in terms of exposure or behaviors such as frequency and timing of sexual intercourse. They may also be atypical in terms of fecundity (Figures $2 \mathrm{~A}$ and B). The current-duration approach allows inclusion of such couples, if the inclusion criteria correspond to women who currently have unprotected intercourse even without the intention to become pregnant.

Our choice not to base the eligibility criteria on the woman declaring that she is currently trying to become pregnant was moreover motivated by the fact that the understanding of the notion of pregnancy wantedness or planning may vary among women and may strongly depend on the duration of involuntary infecundity at the time of the questionnaire; it may also 
depend on age, reproductive history ${ }^{25}$ and the couple's knowledge about their fecundity. After a couple of years of infertility, some couples who stopped using birth control methods in order to become pregnant may conclude that they are sterile, or may say they are no longer trying to become pregnant even though they are having unprotected intercourse. In the absence of systematic medical examinations after a given duration of involuntary infertility, it seems that excluding these (probably subfertile) couples who state they are not trying to become pregnant would limit the reproducibility of the approach.

When we restricted our study population to the pregnancy planners (defined as above), the estimated effect of tobacco smoking decreased (adjusted time ratio $=1.5,95 \% \mathrm{Cl}, 0.7-3.5$; $\mathrm{n}=51$ ). Whether this change is due to a simple loss of statistical power due to the decrease by about one fifth in the sample size, or to a bias in one analysis, remains to be investigated. This sensitivity analysis illustrates the importance of issues related to pregnancy wantedness, and the relatively high proportion of couples who started a period of unprotected intercourse without planning to become pregnant, when sampled with a currentduration design.

\section{Selection biases}

We can use the screening phase of the study to describe selection bias. We compared the contacted women age 18-44 years with women included in a study based on a sub-sample of the 1999 French national census and including about 380,000 subjects. ${ }^{36}$ When an address contained several women, we selected one woman (as we did in our study). Questions common to both studies were phrased exactly the same way but their context differed. Women under the age of 30 years and those not living with a partner were underrepresented in our study compared to the reference population (Table 5). Also, the women in our study did not have the same number of children and had more education. The differences in the number of children became much smaller when we corrected for the age differences (Table 5). The under-representation in our study population of women under the age of 30 years and of those not living with a partner may be because we did not contact 
people who had only a mobile phone. These people are more likely to be young and single and may represent about $15 \%$ of the adult population in France. ${ }^{37}$ Although the proportion of subjects eligible for a study such as ours may be low in such a population, efforts to contact them could be made in future studies.

\section{DISCUSSION}

Although the idea of studying "current durations" has already been used in demographic and sociologic research, ${ }^{22}$ the current-duration approach has not been implemented in the field of fecundity studies. We have shown that it is possible to recruit a cross-sectional sample of sexually-active couples not using any method to avoid pregnancy, and to determine the current duration of unprotected intercourse. This duration can then be used to estimate the proportion of couples not pregnant after a given number of months of unprotected intercourse. ${ }^{17,20}$ This duration can also be used to estimate the adjusted effect on fecundity of environmental factors without need to follow up the couples.

Sexually active couples currently not using any birth control can also be included in prospective studies (prevalent cohort design), as well as in retrospective studies, although this may not correspond to standard practice. Our results are therefore also of interest for other designs. The specificity of the current-duration approach is that it relies solely on this group.

It is too early to conclude whether the current-duration approach is a good option for monitoring fecundity. Populations from different countries or time periods may differ in frequency of pregnancy planning, in their use assisted reproductive techniques, or in their persistence in trying to become pregnant. ${ }^{38}$ Such differences could bias the estimates provided by this approach. However, this type of limitation is general to all types of fecundity studies. $^{27,38,39}$ 


\section{Use of the current-duration approach to study the influence of environmental exposures on fecundity}

For environmental exposures, the relevant window of exposure of current-duration studies should include the start of the period of unprotected intercourse, as for incident cohort and retrospective TTP studies. In the case of smoking, for instance, women who have been trying to become pregnant for a long time have more opportunity and incentive to quit smoking than women who just started an attempt at pregnancy, so that current smoking should not be used as an exposure variable. If male exposures are of interest and if they are to be assessed using questionnaires, then it might be preferable to refer to the date corresponding to the start of the period of unprotected intercourse (or to collect the whole history of past exposures) rather than to explicitly mention "the time when you/your partner last stopped using a method to avoid pregnancy." Taking into account environmental exposures as timedependent covariates would also be relevant. Although there is a theoretical frame for the

use of time-dependent covariates in AFT models, ${ }^{40(p .66)}$ further developments are necessary for their practical implementation in the current-duration approach.

\section{Study options}

Couples who have long durations of attempting pregnancy (corresponding to the least fecund couples) are over-represented in the current-duration design because the probability of being included in a cross-sectional study increases as the total duration of unprotected intercourse increases. This over-representation due to length-biased sampling is accounted for in the statistical analysis. For a given sample size, this may increase statistical power compared with a cohort approach, in which a couple waiting a long time has the same probability of being included as a couple waiting a short time. Formal comparisons of statistical power and bias among various study designs are needed to confirm this hypothesis. Moreover, these approaches should not be competing but rather be viewed as complementary. Indeed, the follow-up of the cross-sectional sample of couples obtained in the current-duration design until the end of the period of unprotected intercourse (Figure 1) can be seen as a mixture of 
these two designs. This corresponds to the prevalent-cohort design. ${ }^{18,21}$ We are currently carrying out such a follow-up of our study population. This approach already suggested ${ }^{18,}$ ${ }^{p .593}$ is an interesting option for prospective studies, in that the eligibility rate may be about five times higher than in an incident cohort. A related idea has been proposed by Olsen and Andersen. ${ }^{19}$

The recruitment of a cross-sectional sample of couples not using contraception (and in particular not using hormonal contraception) also provides an interesting opportunity to study menstrual cycle function. ${ }^{41}$

In summary, the current-duration approach has a higher eligibility rate than incident cohorts relying on couples who will soon start an attempt at pregnancy; it also allows estimation of the probability of pregnancy and the assessment of the influence of environmental factors on fecundity, adjusting for confounders. The approach potentially suffers from several biases previously described for other types of TTP studies, in particular those due to temporal trends in prevalence of exposure or due to the exclusion of couples who became pregnant while using a contraceptive method. For most of these potential biases, approaches have been proposed to quantify or correct them, so that the current-duration design -and presumably the prevalent cohort design- appear to be practical options for fecundity studies. 


\section{ACKNOWLEDGEMENTS}

We thank all the team of the Atoo institute (Paris), in particular the interviewers and Florence Philène for her useful comments during the CATI implementation of the questionnaire. We thank Cécile Lefèvre (Ined) for having given us access to the study "Etude de l'Histoire Familiale" and Laurent Toulemon for his methodological help with this study. We thank Alfred Spira for his support in initiating the study. We also thank Claire Pinçon for useful discussions and Benjamin Granger, Lyliane Rosetta and Anne Etchevers for their role in other aspects of the study. 


\section{REFERENCES}

1. Baird DD, Wilcox AJ, Weinberg CR. Use of time to pregnancy to study environmental exposures. Am J Epidemiol 1986;124(3):470-80.

2. Bonde JP, Ernst E, Jensen TK, Hjollund NH, Kolstad H, Henriksen TB, Scheike T, Giwercman A, Olsen J, Skakkebaek NE. Relation between semen quality and fertility: a population-based study of 430 first-pregnancy planners. Lancet 1998;352(9135):1172-7.

3. Toppari J, Larsen JC, Christiansen P, Giwercman A, Grandjean P, Guillette LJ, Jr., Jegou B, Jensen TK, Jouannet P, Keiding N, Leffers H, McLachlan JA, Meyer O, Muller J, Rajpert-De Meyts E, Scheike T, Sharpe R, Sumpter J, Skakkebaek NE. Male reproductive health and environmental xenoestrogens. Environ Health Perspect 1996;104 Suppl 4:741-803.

4. Slama R, Kold-Jensen T, Scheike T, Ducot B, Spira A, Keiding N. How would a decline in sperm concentration over time influence the probability of pregnancy? Epidemiology 2004;15(4):458-65.

5. Joffe M. Invited commentary: the potential for monitoring of fecundity and the remaining challenges. Am J Epidemiol 2003;157(2):89-93.

6. Olsen J, Rachootin P. Invited Commentary: Monitoring Fecundity over Time-If We Do It, Then Let's Do It Right. Am J Epidemiol 2003;157(2):94-7.

7. Joffe M, Key J, Best N, Keiding N, Scheike T, Jensen TK. Studying time to pregnancy by use of a retrospective design. Am J Epidemiol 2005;162(2):115-24.

8. Sallmen M, Lindbohm ML, Nurminen M. Paternal exposure to lead and infertility. Epidemiology 2000;11(2):148-52.

9. Jensen TK, Scheike T, Keiding N, Schaumburg I, Grandjean P. Selection bias in determining the age dependence of waiting time to pregnancy. American Journal of Epidemiology 2000;152(6):565-72. 
10. Juul S, Keiding N, Tvede M. Retrospectively sampled time-to-pregnancy data may make age-decreasing fecundity look increasing. European Infertility and Subfecundity Study Group. Epidemiology 2000;11(6):717-9.

11. Baird DD, Wilcox AJ, Weinberg CR, Kamel F, McConnaughey DR, Musey PI, Collins DC. Preimplantation hormonal differences between the conception and nonconception menstrual cycles of 32 normal women. Hum Reprod 1997;12(12):260713.

12. Wilcox A, Weinberg C, Baird D. Caffeinated beverages and decreased fertility [see comments]. Lancet 1988;2(8626-8627):1453-6.

13. Buck GM, Lynch CD, Stanford JB, Sweeney AM, Schieve LA, Rockett JC, Selevan SG, Schrader SM. Prospective pregnancy study designs for assessing reproductive and developmental toxicants. Environ Health Perspect 2004;112(1):79-86.

14. Slama R, Ducot B, Keiding N, Bouyer J. Correspondence: studying human fertility and environmental exposures. Environ Health Perspect 2004;112(11):A604.

15. Joffe M, Key J, Best N, Jensen TK. Studying human fertility. Environ Health Perspect 2004;112(11):A604-5; author reply A605-6.

16. Jensen TK, Joffe M, Scheike T, Skytthe A, Gaist D, Christensen K. Time trends in waiting time to pregnancy among Danish twins. Hum Reprod 2005;20(4):955-64.

17. Keiding N, Kvist K, Hartvig $\mathrm{H}$, Tvede M, Juul S. Estimating time to pregnancy from current durations in a cross-sectional sample. Biostatistics 2002;3:565-578.

18. Weinberg CR, Wilcox AJ. Reproductive epidemiology. In: Rothman KJ, Greenland S, eds. Modern Epidemiology. Washington: Lippincott-Raven, 1998;585-608.

19. Olsen J, Andersen PK. We should monitor human fecundity, but how? A suggestion for a new method that may also be used to identify determinants of low fecundity. Epidemiology 1999;10(4):419-21.

20. Weinberg CR, Gladen BC. The beta-geometric distribution applied to comparative fecundability studies. Biometrics 1986;42(3):547-60. 
21. Keiding N. Independent delayed entry (with discussion). In: Klein JP, Goel PK, eds. Survival analysis: State of the Art. Dordrecht: Kluwer, 1992;309-326.

22. Yamaguchi K. Accelerated failure-time mover-stayer regression models for the analysis of last-episode data. Sociological Methodology 2003;33:81-110.

23. Keiding N, Fine JP, Carstensen L, Slama R. Accelerated failure time regression for backward recurrence times and current durations. Research report 05/4. Copenhagen: Department of Biostatistics, University of Copenhagen, 2005.

24. The eligibility questionnaire is available at the following URL: http://u569.kb.inserm.fr/web569/fertil/questfr.pdf

25. Kaufmann RB, Morris L, Spitz AM. Comparison of two question sequences for assessing pregnancy intentions. Am J Epidemiol 1997;145(9):810-6.

26. Bonde JP, Hjollund NH, Jensen TK, Ernst E, Kolstad H, Henriksen TB, Giwercman A, Skakkebaek NE, Andersson AM, Olsen J. A follow-up study of environmental and biologic determinants of fertility among 430 Danish first-pregnancy planners: design and methods. Reprod Toxicol 1998;12(1):19-27.

27. Baird DD, Weinberg CR, Schwingl P, Wilcox AJ. Selection bias associated with contraceptive practice in time-to-pregnancy studies. Ann N Y Acad Sci 1994;709:15664.

28. Efron B, Tibshirani R. An introduction to the bootstrap. Monographs on statistics and applied probability. New York: Chapman \& Hall, 1993.

29. James I. Accelerated Failure-time Models. In: Armitage P, Colton T, eds. Encyclopedia of Biostatistics. Vol. 1. Chichester: John Wiley \& Sons, 1998;26-30.

30. Jensen TK, Henriksen TB, Hjollund NH, Scheike T, Kolstad H, Giwercman A, Ernst E, Bonde JP, Skakkebaek NE, Olsen J. Adult and prenatal exposures to tobacco smoke as risk indicators of fertility among 430 Danish couples. Am J Epidemiol 1998;148(10):992-7. 
31. Basso O, Juul S, Olsen J. Time to pregnancy as a correlate of fecundity: differential persistence in trying to become pregnant as a source of bias. Int J Epidemiol 2000;29(5):856-61.

32. Weinberg CR, Baird DD, Rowland AS. Pitfalls inherent in retrospective time-to-event studies: the example of time to pregnancy. Stat Med 1993;12(9):867-79.

33. Weinberg CR, Baird DD, Wilcox AJ. Sources of bias in studies of time to pregnancy. Stat Med 1994;13(5-7):671-81.

34. Basso O, Olsen J, Bisanti L, Juul S, Boldsen J. Are seasonal preferences in pregnancy planning a source of bias in studies of seasonal variation in reproductive outcomes? The European Study Group on Infertility and Subfecundity. Epidemiology $1995 ; 6(5): 520-4$

35. Guilbert P, Baudier F, Gautier A, eds. Baromètre Santé 2000-Résultats. Vanves: INPES, 2001.

36. Lefevre C, Filhon A, eds. Histoires de familles, histoires familiales. Les résultats de l'enquête Famille de 1999. Les cahiers de I'INED. Paris: INED, 2005.

37. Bigot R. La diffusion des technologies de l'information dans la société française (2004). Research report Paris: CREDOC, 2004. http://www.arttelecom.fr/publications/etudes/et-credoc2004.pdf

38. Sallmen M, Weinberg CR, Baird DD, Lindbohm ML, Wilcox AJ. Has Human Fertility Declined Over Time? Why We May Never Know. Epidemiology 2005;16(4):494-499.

39. Tuntiseranee P, Olsen J, Chongsuvivatwong V, Limbutara S. Fecundity in Thai and European regions: results based on waiting time to pregnancy. Hum Reprod $1998 ; 13(2): 471-7$.

40. Cox DR, Oakes D. Analysis of Survival Data. Monographs on Statistics and Applied Probability. London: Chapman and Hall, 1984.

41. Waller K, Swan SH, Windham GC, Fenster L, Elkin EP, Lasley BL. Use of urine biomarkers to evaluate menstrual function in healthy premenopausal women. Am J Epidemiol 1998;147(11):1071-80. 
42. Jensen TK, Keiding N, Scheike T, Slama R, Spira A. Declining human fertility? [letter; comment]. Fertil Steril 2000;73(2):421-3. 


\section{TABLES}

Table 1: Distribution of the 7,699 listed and unlisted randomly generated phone numbers.

\begin{tabular}{|c|c|c|c|c|c|c|}
\hline & \multicolumn{2}{|c|}{ Listed } & \multicolumn{2}{|c|}{ Unlisted } & \multicolumn{2}{|c|}{ Overall } \\
\hline & No. & $(\%)$ & No. & $(\%)$ & No. & $(\%)$ \\
\hline Dialled numbers & 4657 & & 3042 & & 7699 & \\
\hline Not a home phone number & 764 & $(16.4)$ & 1269 & $(41.7)$ & 2033 & $(26.4)$ \\
\hline Remaining numbers & 3893 & (100) & 1773 & $(100)$ & 5666 & $(100)$ \\
\hline No answer or busy (after 15 calls) & 473 & $(12.2)$ & 761 & $(42.9)$ & 1234 & $(21.8)$ \\
\hline No dialogue possible (not French-speaking, etc.) & 86 & (2.2) & 33 & $(1.9)$ & 119 & (2.1) \\
\hline Refusal to answer any question & 88 & (2.3) & 48 & $(2.7)$ & 136 & (2.4) \\
\hline Answering machine & 76 & (2.0) & 43 & (2.4) & 119 & (2.1) \\
\hline Home, someone answered and did not refuse & 3170 & $(81.4)$ & 888 & $(50.1)$ & 4058 & $(71.6)$ \\
\hline Home, someone answered and did not refuse & 3170 & (100) & 888 & $(100)$ & 4058 & $(100)$ \\
\hline \multicolumn{7}{|l|}{ Women age $18-50$ years in the home } \\
\hline 0 & 1871 & $(59.0)$ & 509 & $(57.3)$ & 2380 & $(58.6)$ \\
\hline$\geq 1$ & 1299 & $(41.0)$ & 379 & $(42.7)$ & 1678 & $(41.4)$ \\
\hline Homes with a woman age $18-50$ years & 1299 & (100) & 379 & $(100)$ & 1678 & $(100)$ \\
\hline Refusal before eligibility questionnaire & 147 & $(11.3)$ & 48 & $(12.7)$ & 195 & $(11.6)$ \\
\hline Answered eligibility questionnaire & 1152 & $(88.7)$ & 331 & $(87.3)$ & 1483 & $(88.4)$ \\
\hline Age 18-44 years & 929 & $(80.6)$ & 275 & (83.1) & 1204 & (81.2) \\
\hline
\end{tabular}


Table 2: Characteristics at interview of the 1204 women age 18-44 years who answered the eligibility questionnaire, and of the current-duration group (see text for definition).

\begin{tabular}{|c|c|c|c|c|c|c|}
\hline & \multicolumn{2}{|c|}{$\begin{array}{l}\text { Whole population } \\
\qquad(\mathrm{n}=1204)\end{array}$} & \multicolumn{4}{|c|}{ Current-duration group } \\
\hline & \multirow[b]{2}{*}{$\mathrm{n}$} & \multirow[b]{2}{*}{$\%$} & \multicolumn{2}{|c|}{$\begin{array}{c}\text { No } \\
(n=1135)\end{array}$} & \multicolumn{2}{|r|}{$\begin{array}{c}\text { Yes } \\
(n=69)\end{array}$} \\
\hline & & & $\mathrm{n}$ & $\left(\%{ }^{*}\right)$ & $\mathrm{n}$ & $(\% *)$ \\
\hline \multicolumn{7}{|l|}{ Age at interview (years) } \\
\hline $18-24$ & 173 & 14.4 & 169 & $(97.7)$ & 4 & (2.3) \\
\hline $25-29$ & 181 & 15.0 & 165 & $(91.2)$ & 16 & $(8.8)$ \\
\hline $30-34$ & 285 & 23.7 & 263 & $(92.3)$ & 22 & $(7.7)$ \\
\hline $35-39$ & 311 & 25.8 & 292 & (93.9) & 19 & $(6.1)$ \\
\hline $40-44$ & 254 & 21.1 & 246 & $(96.9)$ & 8 & $(3.2)$ \\
\hline \multicolumn{7}{|l|}{ Currently lives with a male partner } \\
\hline Yes & 945 & 78.5 & 877 & $(92.8)$ & 68 & $(7.2)$ \\
\hline No & 259 & 21.5 & 258 & $(99.6)$ & 1 & $(0.4)$ \\
\hline \multicolumn{7}{|l|}{ Number of children } \\
\hline 0 & 376 & 31.2 & 345 & $(91.8)$ & 31 & (8.2) \\
\hline 1 & 253 & 21.0 & 237 & $(93.7)$ & 16 & (6.3) \\
\hline 2 & 391 & 32.5 & 375 & (95.9) & 16 & $(4.1)$ \\
\hline 3 and more & 184 & 15.3 & 178 & $(96.7)$ & 6 & (3.3) \\
\hline \multicolumn{7}{|l|}{ Current contraception } \\
\hline No contraception & 165 & 13.7 & 96 & $(58.2)$ & 69 & $(41.8)$ \\
\hline Uses contraception & 1036 & 86.1 & 1036 & $(100)$ & 0 & $(0)$ \\
\hline Do not know & 3 & 0.3 & 3 & $(100)$ & 0 & (0) \\
\hline \multicolumn{7}{|c|}{ Eligible in the current-duration group } \\
\hline Yes & 69 & 5.7 & 0 & $(0)$ & 69 & $(100)$ \\
\hline No & 1135 & 94.3 & 1135 & $(100)$ & 0 & $(0)$ \\
\hline \multicolumn{7}{|c|}{ Planning to try to become pregnant } \\
\hline Yes, currently trying ${ }^{\dagger}$ & 88 & 7.3 & 36 & $(40.9)$ & 52 & $(59.1)$ \\
\hline Yes, within 3 months & 3 & 0.2 & 3 & $(100)$ & 0 & (0) \\
\hline Yes, within 4-6 months & 12 & 1.0 & 12 & $(100)$ & 0 & $(0)$ \\
\hline Yes, within 7-12 months & 33 & 2.7 & 33 & $(100)$ & 0 & $(0)$ \\
\hline Yes, in more than 12 months & 106 & 8.8 & 103 & $(97.2)$ & 3 & $(2.8)$ \\
\hline Yes, but not planned when & 355 & 29.5 & 352 & $(99.2)$ & 3 & $(0.8)$ \\
\hline No & 548 & 45.5 & 537 & $(98.0)$ & 11 & (2.0) \\
\hline Currently pregnant & 59 & 4.9 & 59 & $(100)$ & 0 & (0) \\
\hline
\end{tabular}

* Row percentages. 
"Answer of the woman to the question: "Are you currently trying to become pregnant," independent of her status with regards to contraception and frequency of intercourse. 
Table 3: Current duration of unprotected intercourse (CDUI) and time ratios associated with women's tobacco consumption among 69 sexually active couples not currently using contraception. Accelerated failure-time models, either unadjusted or adjusted for all characteristics from the table.

\begin{tabular}{|c|c|c|c|c|c|c|c|}
\hline \multirow[b]{2}{*}{ Characteristic } & \multicolumn{4}{|c|}{ Raw models } & \multicolumn{3}{|c|}{ Adjusted model } \\
\hline & No. & $\begin{array}{l}\text { CDUI }^{*} \text { (months) } \\
\text { mean (median) }\end{array}$ & $\begin{array}{l}\text { Time } \\
\text { ratio }^{\dagger}\end{array}$ & $(95 \% \mathrm{Cl})$ & No. & $\begin{array}{l}\text { Time } \\
\text { ratio }^{\dagger}\end{array}$ & $(95 \% \mathrm{Cl})$ \\
\hline
\end{tabular}

Female tobacco consumption ${ }^{\ddagger}$

\begin{tabular}{lllllllll} 
No & 35 & 22 & $(9)$ & 1.0 & \multicolumn{5}{c}{33} & 1.0 \\
Yes & 33 & 39 & $(24)$ & 2.18 & $(1.06-4.50)$ & 32 & 2.40 & $(1.11-5.19)$
\end{tabular}

Female age (years) $)^{\ddagger}$

$\begin{array}{lrrrrrrrr}18-24 & 6 & 50 & (19) & 2.14 & (0.52-8.74) & 6 & 2.32 & (0.57-9.56) \\ 25-29 & 24 & 33 & (9) & 1.0 & & 23 & 1.0 & \\ 30-34 & 25 & 30 & (10) & 1.18 & (0.49-2.84) & 23 & 1.02 & (0.43-2.43) \\ 35-39 & 12 & 28 & (19) & 1.34 & (0.45-3.99) & 11 & 1.16 & (0.39-3.39) \\ 40-44 & 2 & 11 & (11) & 0.85 & (0.09-8.19) & 2 & 0.45 & (0.05-4.45)\end{array}$

Frequency of sexual intercourse

$\begin{array}{lrrrrrrrr}<1 \text { per month } & 2 & 39 & (39) & 1.04 & (0.11-9.99) & 2 & 2.16 & (0.23-20.1) \\ 1-3 \text { per month } & 15 & 32 & (18) & 1.98 & (0.67-5.85) & 15 & 2.08 & (0.70-6.15) \\ 1-2 \text { per week } & 35 & 38 & (15) & 2.38 & (0.96-5.90) & 32 & 2.36 & (0.96-5.78) \\ \geq 3 \text { per week } & 16 & 12 & (6) & 1.0 & & & 16 & 1.0\end{array}$

Mean menstrual cycle length (days)

\begin{tabular}{lllllllll}
$<27$ & 22 & 26 & $(10)$ & 1.0 & \multicolumn{5}{c}{22} & 1.0 \\
$27-29$ & 27 & 30 & $(14)$ & 1.20 & $(0.50-2.92)$ & 27 & 1.39 & $(0.57-3.42)$ \\
$\geq 30$ & 16 & 35 & $(9)$ & 1.65 & $(0.60-4.55)$ & 16 & 2.24 & $(0.83-6.06)$
\end{tabular}

* Due to the population sampling approach, the mean and median current duration cannot be interpreted as the mean or median TTP from a prospective or pregnancy-based study.

${ }^{\dagger}$ The Time Ratio can be considered as an estimate of the ratio of the median of the total duration of unprotected intercourse between the compared groups. A value greater than one 
indicates an increased duration of unprotected intercourse in the exposed group, compared to the reference group.

${ }^{\ddagger}$ At the start of the period of unprotected intercourse. 
Table 4: Bias in time-to-pregnancy studies aimed at estimating the influence of an exposure on fecundity, according to study type:

pregnancy-based (PB), historically prospective (HP), incident ("classical") cohort (IC), prevalent cohort (PC), or current-duration (CD).

Adapted and extended from Weinberg and colleagues. ${ }^{33}$

\begin{tabular}{|c|c|c|c|}
\hline Hypothesis & Corresponding biases & Study type in which bias may occur & How to guard against bias \\
\hline $\begin{array}{l}\text { Exposure is constant during the } \\
\text { period of unprotected intercourse }\end{array}$ & Behavior modification bias. & All 5 approaches & $\begin{array}{l}\text { Use date of discontinuation of contraception as a } \\
\text { reference date. Assess modifications of behavior } \\
\text { and use a model with time-dependent covariates. }\end{array}$ \\
\hline $\begin{array}{l}\text { Stationarity over time of initiation } \\
\text { times }\end{array}$ & $\begin{array}{l}\text { Bias due to time trends in initiation } \\
\text { times. }\end{array}$ & $\mathrm{PB}, \mathrm{HP}, \mathrm{CD}$ & $\begin{array}{l}\text { Appropriately define the study period (HP, PB). }{ }^{42} \\
\text { Weighting approach as suggested here (CD). }\end{array}$ \\
\hline $\begin{array}{l}\text { Prevalence of exposure is } \\
\text { constant over time }\end{array}$ & $\begin{array}{l}\text { Bias due to time trends in exposure } \\
\text { prevalence (if there are also time } \\
\text { trends in fecundity). }\end{array}$ & $\mathrm{PB}, \mathrm{HP}, \mathrm{CD}$ & $\begin{array}{l}\text { Simulation using external data on the time trends in } \\
\text { exposure. }^{32}\end{array}$ \\
\hline \multirow[t]{5}{*}{$\begin{array}{l}\text { Probability of inclusion does not } \\
\text { depend on fecundity level and on } \\
\text { TTP }\end{array}$} & $\begin{array}{l}\text { Pregnancy planning bias }(1) \text { : } \\
\text { exclusion of unplanned/"accidental" } \\
\text { pregnancies. }\end{array}$ & All 5 approaches & $\begin{array}{l}\text { Ascertain exposures for non-planners as well (HP, } \\
\mathrm{PB} \text { ), or among a sub-sample of women with an } \\
\text { unplanned pregnancy (CD, IC and PC) }{ }^{7,27}\end{array}$ \\
\hline & $\begin{array}{l}\text { Pregnancy planning bias (2): } \\
\text { unplanned pregnancies can } \\
\text { retrospectively be described as } \\
\text { planned ("wantedness bias"). }\end{array}$ & PB, HP & $\begin{array}{l}\text { Reanalyze excluding apparent cycle-one } \\
\text { conceptions. Use contraceptive use rather than } \\
\text { pregnancy wish as an inclusion criterion. }\end{array}$ \\
\hline & $\begin{array}{l}\text { Pregnancy planning bias ( } 3 \text { ): } \\
\text { exclusion of couples who have } \\
\text { unprotected intercourse without } \\
\text { planning to become pregnant. }\end{array}$ & PB, HP, IC & $\begin{array}{l}\text { Try to include periods of unprotected intercourse } \\
\text { corresponding to couples not planning to become } \\
\text { pregnant and reanalyze. }\end{array}$ \\
\hline & $\begin{array}{l}\text { Exclusion/under-representation of the } \\
\text { involuntarily infertile couples. }\end{array}$ & PB, maybe HP & $\begin{array}{l}\text { Try to assess the existence of unsuccessful attempts } \\
\text { at pregnancy. }\end{array}$ \\
\hline & Truncation (under-representation of & $\mathrm{PB}$ & Define the study period with respect to the date of \\
\hline
\end{tabular}


short TTPs at the beginning of the

study period and, symmetrically, of

long TTPs at the end of the study

period). ${ }^{42}$

Over-representation of "super

pregnancy planners". ${ }^{14}$

Differences in desired or achieved

family size.

Delay in recognition of pregnar
is similar across exposure
categories

Probability of censoring does not depend on the outcome of the period of unprotected intercourse (non-informative censoring)
Pregnancy recognition bias.

Bias due to differential persistence in trying.

Medical intervention bias.
IC

All 5 approaches

All 5 approaches

$\mathrm{PB}, \mathrm{CD}$

All 5 approaches the beginning (and not the end) of the period of unprotected intercourse; include current attempts.

Follow-up the screened population to detect all attempts at pregnancy.

Provide free standard pregnancy test kits (IC, PC) record when pregnancy was recognized $(C D, H P$, PB); follow-up couples (CD).

Follow-up a sub-sample of exposed and unexposed couples and compare frequency of fertility treatments (CD).

Treat intervention as an exclusion criterion (CD) or a censoring mechanism (IC, HP, PB, PC), and try to assess if censoring is informative. 
Table 5: Characteristics of the 1204 women age 18-44 years who replied to the eligibility questionnaire, and comparison with the study Enquête de l'Histoire Familiale (EHF) ${ }^{36}$ (assumed to be representative of the French general population from 1999).

\section{Contacted women}

$(n=1204)$
EHF study

$(n=380481)$

\section{Crude Standardized ${ }^{*}$}

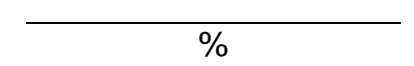

$\%$

\section{Woman age (years)}

$18-24$

$25-29$

30-34

$35-39$

40-44

Currently lives with a partner

Yes

No

Number of children ${ }^{\dagger}$

0

1

2

3 and more
14

15

24

26

21

78

22

31

21

32

15

Age at the end of education

$<16$ years

16-17 years

18-19

20-23

$\geq 24$ years

Currently studying
14

15

4

6

21

59

41

61

39

\section{4}

15

24

26

21

$\begin{array}{ll}21 & 26 \\ 19 & 21\end{array}$

40

35

20

20

25

28

15

17 
${ }^{\dagger}$ Including deceased and adopted children. 


\section{FIGURES}

Figure 1: Schema of the five principal study designs for fecundability studies. The thick arrows indicate the duration of unprotected intercourse, which may be collected either prospectively $(\rightarrow)$ or retrospectively $(\leftarrow)$. The sampling time may be either before the start of the period of unprotected intercourse (incident cohort), during this period (current-duration and prevalent-cohort designs) or after this period (pregnancy-based and historically prospective designs).

Figure 2: Survival function of the total duration of unprotected intercourse (solid line) and 95\% confidence limits (dotted curves) among the current-duration group (parametric Pareto curve); A) entire group ( $n=69)$. B) restricted to women who at the start of the period of unprotected intercourse wanted to become pregnant ("pregnancy planners", $n=53$ ). 


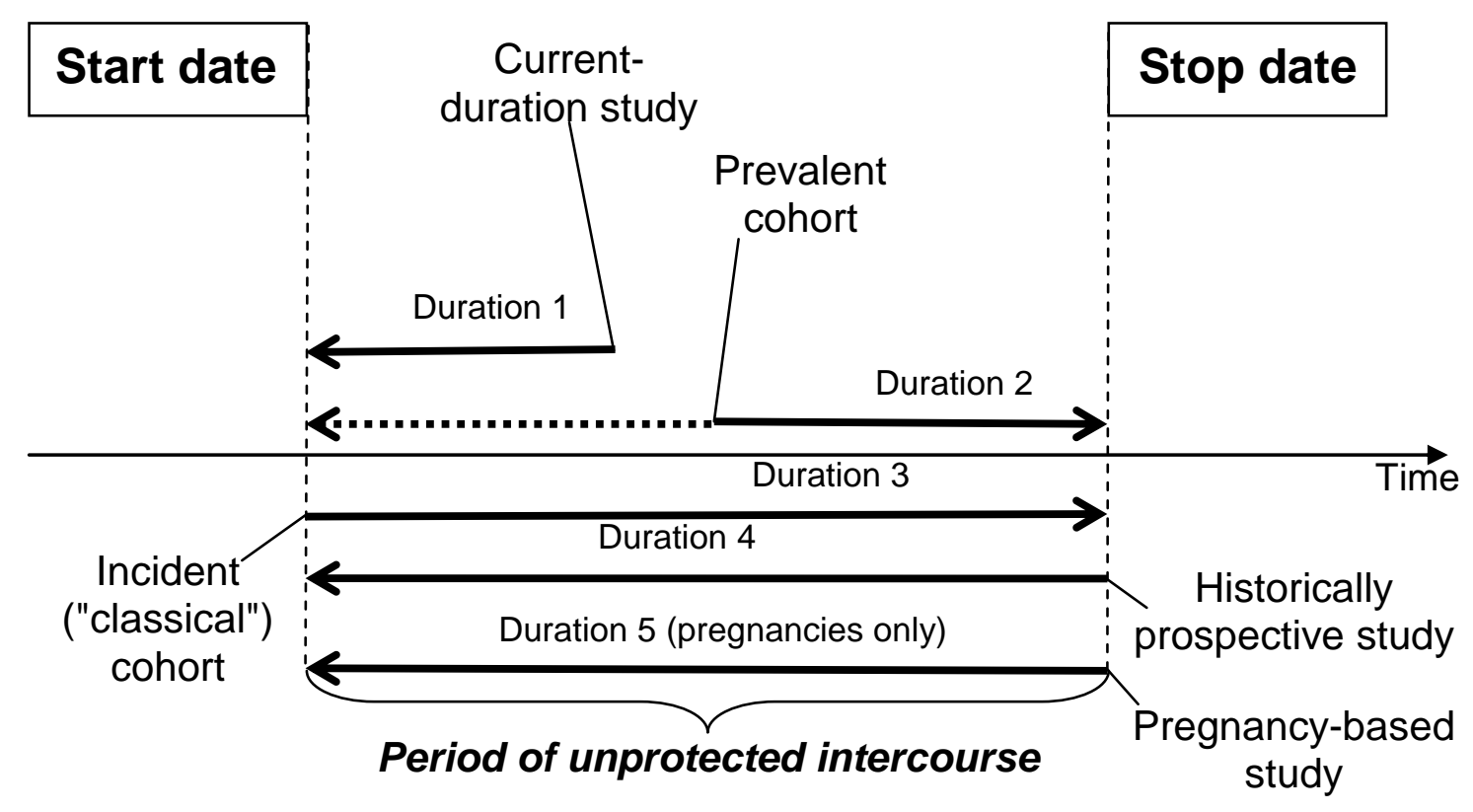

The start date may be either the discontinuation of a method to avoid pregnancy or the end of a pregnancy not followed by use of methods to avoid pregnancy. The stop date may be the beginning of a pregnancy (detected later), the resumption of any method to avoid pregnancy (contraception, sexual abstinence) or the initiation of a medical treatment for infertility. These last two situations correspond to censoring events. Duration 1 corresponds to the current duration of unprotected intercourse.

Time from start date until inclusion (duration 1) is assessed retrospectively whereas time from inclusion to stop date (duration 2) is assessed prospectively.

Duration 5 (pregnancy-based design) is assessed only if a pregnancy is detected at the end of the period of unprotected intercourse. 
A:

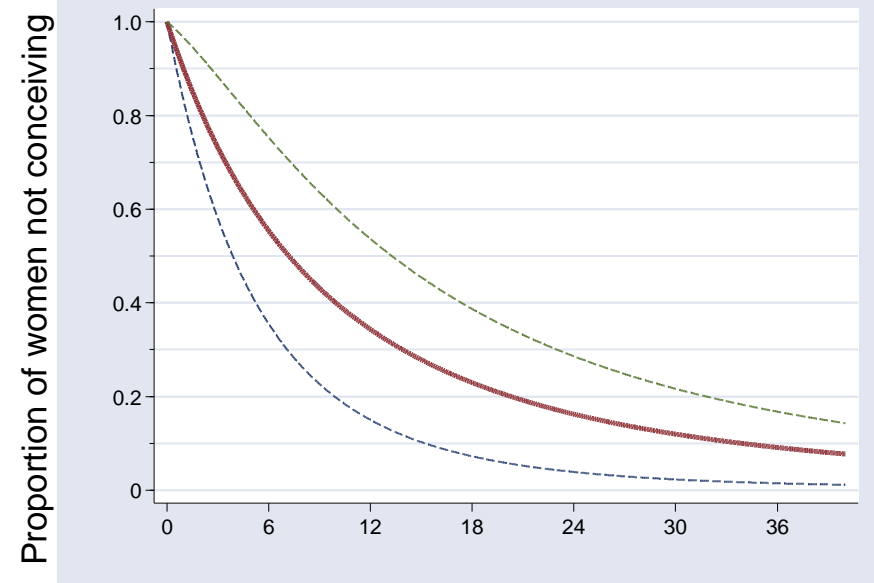

B:

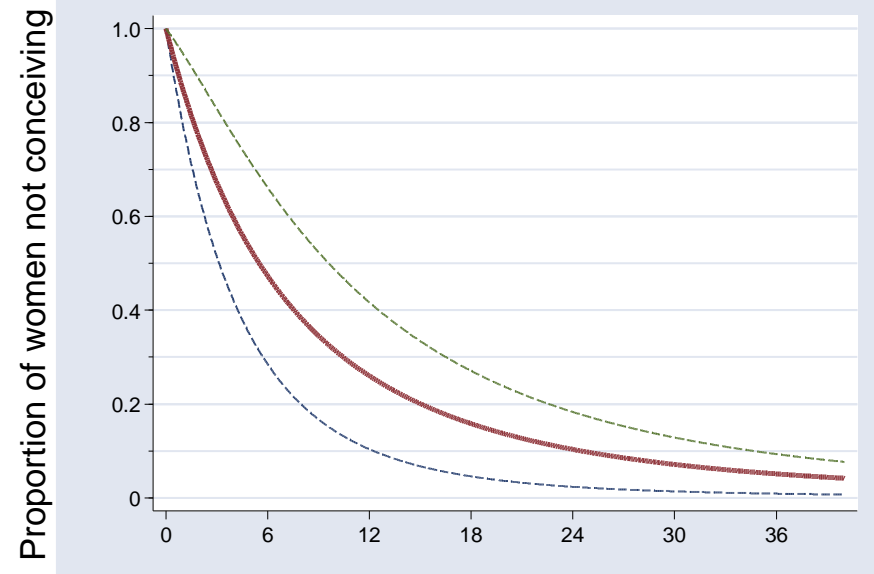

Months of unprotected intercourse 